Claremont Colleges

Scholarship@Claremont

WM Keck Science Faculty Papers

W.M. Keck Science Department

$1-1-1980$

\title{
Kinetics of ADP-induced Human Platelet Shape Change: Apparent Positive Cooperativity
}

John Milton

Claremont McKenna College; Pitzer College; Scripps College

W. Yung

C. Glushak

Mony M. Frojmovic

McGill University

\section{Recommended Citation}

Milton, J.G., W. Yung, C. Glushak, M.M. Frojmovic. "Kinetics of ADP-induced Human Platelet Shape Change: Apparent Positive Cooperativity." Canadian Journal of Physiology and Pharmacology 58.1 (January 1980): 45-52. DOI: 10.1139/y80-009

This Article is brought to you for free and open access by the W.M. Keck Science Department at Scholarship @ Claremont. It has been accepted for inclusion in WM Keck Science Faculty Papers by an authorized administrator of Scholarship @ Claremont. For more information, please contact scholarship@cuc.claremont.edu. 


\title{
Kinetics of ADP-induced human platelet shape change: apparent positive cooperativity ${ }^{1}$
}

\author{
John G. Milton, ${ }^{2}$ W. Yung, ${ }^{3}$ C. Gl.ushak, ${ }^{2}$ and M. M. Frojmovic ${ }^{4}$ \\ Department of Physiology, McGill University, Montreal, P.Q., Canada
}

Received February 21, 1979

Mrtton, J. G., W. Yung, C. Glushak, and M. M. Frojmovic. 1980. Kinetics of ADP-induced human platelet shape change: apparent positive cooperativity. Can. J. Physiol. Pharmacol. 58, 45-52.

The kinetics of ADP-induced human platelet shape change have been examined. Initial velocities of platelet shape change were estimated by two methods: $(l)$ the slope of the initial decrease in light transmission through stirred, citrated platelet-rich plasma, and (2) direct examination of platelet morphologies by phase-contrast microscopy. In both cases, a value of the Hill coefficient, $N_{H}$, significantly greater than 1 is obtained $(2.0 \pm 0.2$ and $1.8 \pm 0.2$, respectively). The observed elevated value of $N_{\mathrm{H}}$ is not due to a substantial fraction of the ADP being platelet bound, the presence of factors in the plasma, platelet heterogeneity, or the influence of the rate of platelet shape change reversion. Our observations suggest that ADP-induced platelet shape change may be a positively cooperative or "threshold" type response.

Milton, J. G., W. YUnG, C. Glushak et M. M. Frojmovic. 1980. Kinetics of ADP-induced human platelet shape change: apparent positive cooperativity. Can. J. Physiol. Pharmacol. 58, 45-52.

On étudie la cinétique du changement de forme des plaquettes humaines induit par de 1'ADP. Les vitesses initiales du changement de forme des plaquettes sont estimées selon deux méthodes: ( 1 ) la pente de la diminution initiale de la transmission de la lumière à travers du plasma agité, citraté et riche en plaquettes, et (2) l'examen direct de la morphologie des plaquettes par microscopie à contraste de phase. On obtient dans les deux cas une valeur du coefficient de Hill, $N_{\mathrm{H}}$, qui est plus grande que celle normalement obtenue ( $2.0 \pm 0.2$ et $1.8 \pm 0.2$, respectivement). La valeur élevée de $N_{H}$ qui est observé n'est pas due à une fraction substantielle d'ADP qui serait liée aux plaquettes, pas plus qu'à la présence de facteurs dans le plasma, à l'hétérogénéité des plaquettes ou à l'influence du taux de réversion du changement de forme des plaquettes. Nos observations suggèrent que le changement de forme des plaquettes induit par de l'ADP pourrait constituer une réponse positivement coopérative ou de type "à seuil."

[Traduit par le journal]

\section{Introduction}

Platelet shape change from smooth, discoid-shaped platelets (discocytes) to more spherical forms with pseudopodal projections (echinocytes) induced by adenosine diphosphate (ADP) is generally regarded as an example of a receptor-mediated process (Born 1965, 1970; Born and Feinberg 1975; Mills and Macfarlane 1975; Nachman and Ferris 1974). Recently, Bennett et al. (1978) have demonstrated that the ADP receptor for shape change may be a membrane polypeptide of 100000 molecular weight. The nature of the mechanism by which the binding of ADP molecules to membranebound receptors is translated into the morphological event of shape change is not precisely known.

The basis for present day discussions of the action of molecules at the receptor level is formed by models first introduced by Clark (1926) which closely resemble those used to describe the interaction of an enzyme with

${ }^{1}$ Supported by the Medical Research Council of Canada (MRCC) (grant MA-3612) and a FCAC grant from the Quebec Education Department.

${ }^{2}$ Faculty of Medicine Award.

${ }^{3}$ MRCC Studentship.

${ }^{4}$ Please address reprint requests to Dr. M. M. Frojmovic Department of Physiology, McIntyre Medical Sciences Building, McGill University, 3655 Drummond Street, Montreal, P.Q., Canada H3G 1 Y6. its substrate. In view of these considerations, the kinetics of ADP-induced platelet shape change can be described in terms of a "Michaelis-Menton-like" model:

$$
\text { [1] } \mathrm{ADP}+\mathrm{R} \underset{k_{2}}{\stackrel{k_{1}}{\rightleftharpoons}} \mathrm{ADP}-\mathrm{R} \stackrel{k_{3}}{\longleftarrow} \text { echinocyte }
$$

where $k_{1}, k_{2}$, and $k_{3}$ are rate constants, $\mathrm{R}$ is a receptor for platelet shape change located on a discocyte, ADP-R is the ADP-receptor complex, and the symbol " $\longrightarrow$ " indicates that the conversion of discocyte to echinocyte may involve additional steps subsequent to the binding of ADP to its receptor, to yield

$$
\text { [2] } V=\frac{V_{\max }[\mathrm{ADP}]_{\mathrm{f}}}{K^{\prime}+[\mathrm{ADP}]_{\mathrm{f}}}
$$

where $V$ and $V_{\max }$ are, respectively, the initial and maximal initial velocities for shape change, $[A D P]_{f}$ is the concentration of free ADP, i.e., that which is not receptor bound, and $K^{\prime}$ is the apparent Michaelis-Menton constant obtained from the $x$-intercept of a plot of $V^{-1}$ versus [ADP] $]_{f}^{-1}$.

Previous studies with rabbit (Born 1970) and human (Favis and Colman 1978) platelets have suggested that 
the kinetics of ADP-induced platelet shape change are consistent with that predicted by $\mathrm{Eq}$. 2 . However, the lowest value of $V$ considered in these studies corresponded to only approximately $30 \%$ of $V_{\text {max }}$. Departures from the description offered by Eq. 2 are anticipated to be most significant at low [ADP], i.e., low V. Moreover, the changes in light transmission utilized by these authors to estimate $V$ may not accurately reflect the rate of platelet shape change, as, for example, changes in platelet refractive index will also affect light transmission (Frojmovic 1978). It is clearly necessary to try to extend the kinetic measurements of shape change to lower values of $V$ with a more direct measure of shape change before any conclusions concerning the nature of the process can be safely drawn.

Here we directly measure $V$ by examining changes in platelet morphology with phase-contrast microscopy. The results are compared with those when $V$ is measured from changes in light transmission. In both cases, it is shown that over a range of [ADP] which extends the measurement of $V$ from $V_{\max }$ to approximately $10 \%$ of $V_{\max }$, Eq. 2 does not provide an adequate description of the kinetics of ADP-induced platelet shape change. A Hill plot, i.e. $\log \left(V /\left(V_{\max }-V\right)\right)$ versus $\log ([A D P])$, is performed. Whereas Eq. 2 predicts that the Hill coefficient, $N_{\mathrm{H}}$, equals 1 , our data yield $N_{\mathrm{H}}>1$. The significance of this observation is discussed.

\section{Methods}

Preparation of platelet-rich plasma (PRP), platelet-freee plasma (PFP), and washed platelets

Normal donors were chosen from healthy men and women between the ages of 20 and 30 years. Blood was drawn by venipuncture into $3.8 \%$ citrate (one volume to nine volumes blood) at $37^{\circ} \mathrm{C}$ and PRP prepared as described previously (Tang and Frojmovic 1977). PFP was prepared by first centrifuging PRP for $15 \mathrm{~min}$ at $1900 \times g, 25^{\circ} \mathrm{C}$, and then centrifuging the supernatant at $30000 \times g, 4^{\circ} \mathrm{C}$, for $15 \mathrm{~min}$. PFP was allowed to incubate at $37^{\circ} \mathrm{C}$ for an additional $30 \mathrm{~min}$ before use to remove residual ADP. Washed platelets were prepared by the method of Mustard et al. (1972) and were generously supplied by Dr. H. L. Goldsmith, McGill University.

Kinetic studies

ADP (Sigma Chemical Co.) was dissolved in $\mathrm{Ca}^{+2}-\mathrm{Mg}^{+2}$ free Tyrodes buffer. One to $10 \mu \mathrm{L}$ ADP was quickly injected using a Hamilton syringe into $0.4 \mathrm{~mL}$ platelet suspension which was contained in a siliconized cuvette $(6.9 \mathrm{~mm} \times 45$ $\mathrm{mm}$ ) with stir bars $(6 \mathrm{~mm} \times 1 \mathrm{~mm})$ spun at $1000 \mathrm{rpm}, 37^{\circ} \mathrm{C}$. Injection of the dye, azure $A$, indicated that under these conditions mixing was complete in less than $1 \mathrm{~s}$. The initial velocity of shape changes, $V$, was estimated by the following two methods.

(a) Changes in light transmission

Changes in light transmission were monitored using the aggregometer apparatus described previously (Frojmovic 1973), using a rapid chart speed (10 inches $/ \mathrm{min} ; 1$ inch $=25.4 \mathrm{~mm}$ ). A rapid decrease in light transmission is observed following the addition of ADP to stirred PRP. The slope of the initial decrease in light transmission was utilized as a measure of $V$. Several other authors (Born 1970; Favis and Colman 1978; Bennett et al. 1978) have utilized this measurement to estimate V.

(b) Phase-contrast microscopy

At $5 \mathrm{~s}$ following the addition of ADP to stirred PRP, 0.05$\mathrm{mL}$ samples were withdrawn and fixed with four volumes of $1.3 \%$ glutaraldehyde at $37^{\circ} \mathrm{C}$ as described previously (Frojmovic and Panjwani 1976; Milton and Frojmovic 1979). This sampling time was chosen as it was found that for all [ADP]'s used in this study, the increase in the fraction of shape-changed platelets, $f_{k}$, was linear for at least the first $6 \mathrm{~s}$ following ADP addition (Fig. 1). The value of $f_{k}$ measured at $5 \mathrm{~s}$ following ADP addition was taken as a measure of $V$. Shape-changed platelets were identified with phase-contrast microscopy (Zeiss universal microscope; magnification $x$ 800 ) as those which possessed at least one pseudopod and (or) whose axial ratio, i.e., the ratio of thickness to diameter, exceeded 0.5 (Milton and Frojmovic 1979). A third criterion which had to be used to identify platelets in the early stages of shape change was the appearance of a rougher or "fuzzy" cell outline under phase-contrast microscopy. This contrasted with the very smooth outline of unactivated platelets. Darkfield microscopy observation indicated that the earlier stages of platelet shape change were associated with the development of short pseudopods and membrane undulations. Control experiments demonstrated that $f_{\mathrm{E}}$ was not altered by the above fixation procedure. In determining $f_{\mathrm{k}}$, at least 400 platelets were randomly selected.

\section{Platelet shape change reversion}

The rate of platelet shape change reversion was estimated as follows. Following the addition of ADP to stirred PRP, the stirring was stopped after complete mixing had occurred to prevent aggregation, $0.025-\mathrm{mL}$ samples were removed as a function of time and fixed with glutaraldehyde, and $f_{\mathrm{E}}$ was determined as described above.

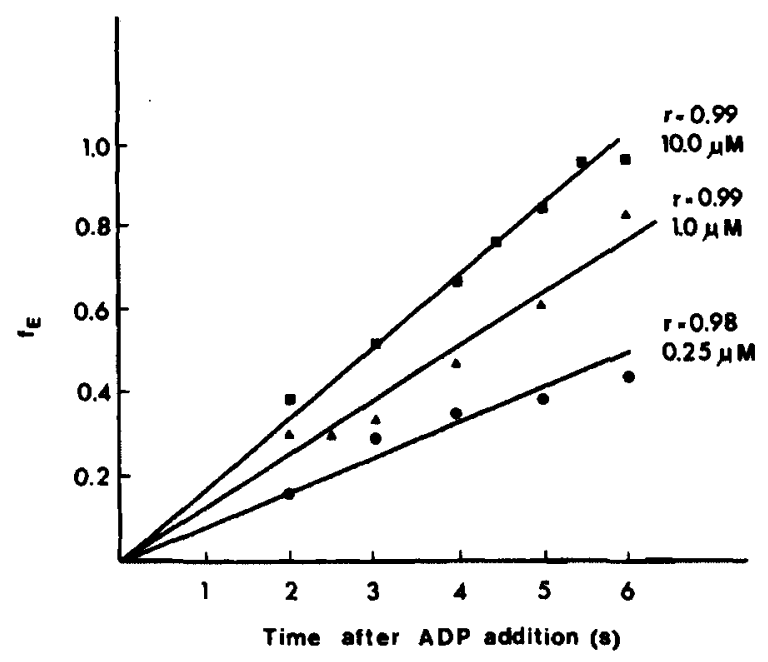

FIG. 1. Fraction of shape-changed platelets $\left(f_{V}\right)$ during the first $6 \mathrm{~s}$ after ADP addition demonstrating the linearity with time over the ADP concentration range used in this study. Correlation coefficients $(r)$ of the three corresponding linear regression lines are shown. $\mathrm{E}, 10.0 \mu M$ ADP; $\Delta, 1.0 \mu M$ $\mathrm{ADP}, 0,0.25 \mu \mathrm{M}$ ADP. 


\section{Results}

The results of a typical experiment showing the effect of total ADP concentration, [ADP], on $V$ as measured by direct examination of platelet morphologies under phase-contrast microscopy are given in Fig. 2A. Although over the concentration range of 0.25-10 $\mu \mathrm{M}$ ADP the plot of $V^{-1}$ versus [ADP] $]^{-1}$ is approximately linear (see dotted line in Fig. 2B), a linear relationship does not hold over the whole concentration range investigated. In particular, there is a pronounced upward curvature as [ADP] becomes smaller. Qualitatively similar trends are observed when $V$ is measured as the initial slope of the decrease in light transmission (see Fig. $2 \mathrm{C}$ and $\mathrm{D}$ ). This demonstrates that the results in Fig. $2 \mathrm{~A}$ and $B$ are not dependent on the method utilized to measure $V$. The observation that a plot of $V^{-1}$ versus $[\mathrm{ADP}]^{-1}$ is not linear demonstrates that the kinetic de- scription implied by Eq. 2 does not provide a valid description for the kinetics of ADP-induced platelet shape change.

Closer examination of the data presented in Fig. 2 A and $\mathrm{C}$ suggests that the curves are sigmoid. Hill plots for these data are shown in Fig. 3. In each case, $N_{H}$ is significantly greater than $1(p<0.05)$. It is important to note that the linear range of the Hill plots includes $V$ 's measured in the more linear range of the plots in Fig. $2 \mathrm{~B}$ and D. $N_{\mathrm{H}}$ and the concentration of ADP required for $1 / 2 V_{\max },[\mathrm{ADP}]_{1 / 2}$, for a number of different donors are summarized in Table 1.

A value of $N_{\mathrm{H}}>1$ is suggestive of some kind of cooperative process or "threshold-type" response for ADPinduced platelet shape change. However, there are other possibilities which may result in a spurious departure from $\mathrm{Eq} .2$
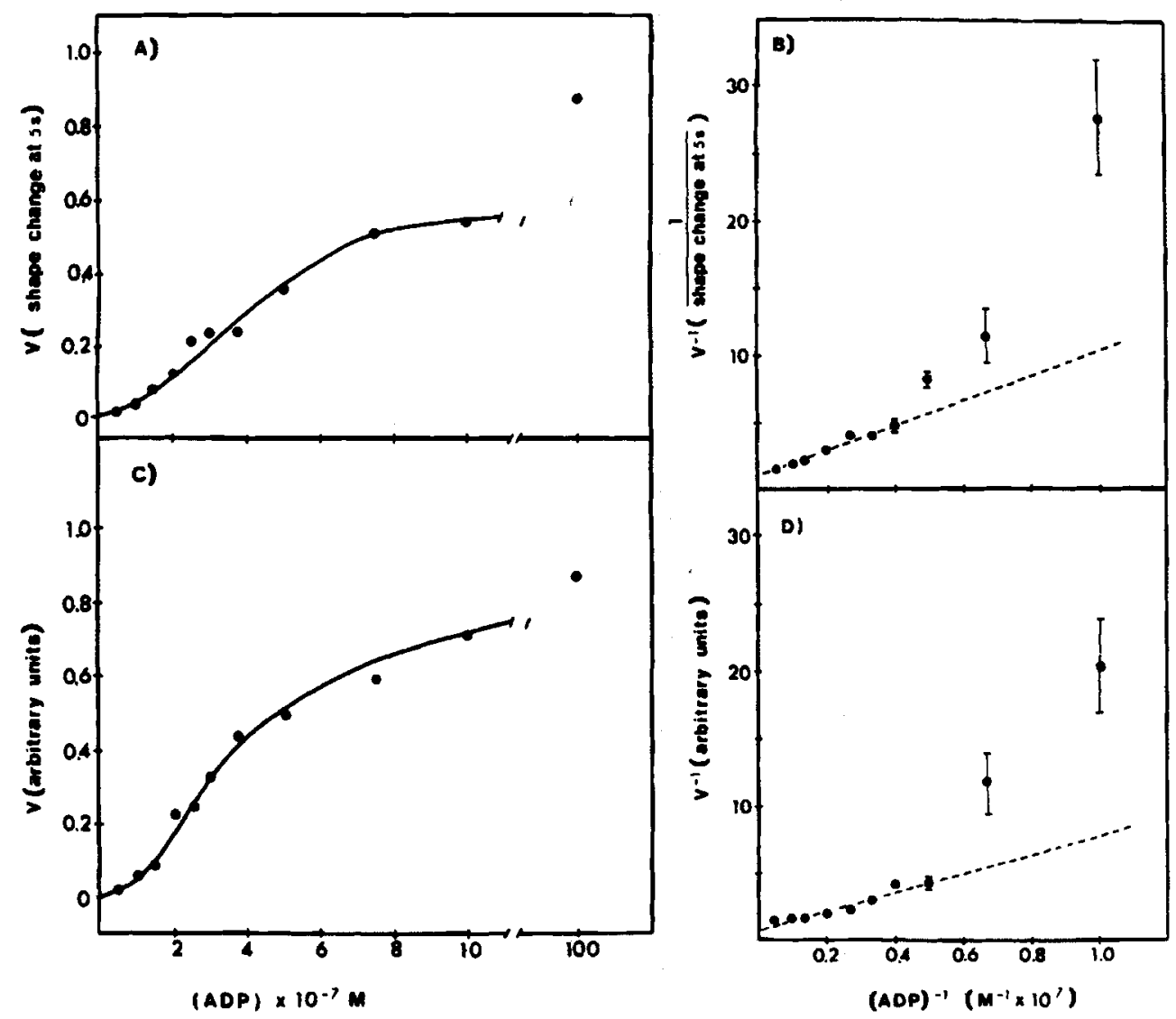

FIG. 2. Effect of ADP concentration on the velocity $(V)$ of the change in shape of human platelets observed in a typical experiment. Donor (donor 1) was female, age 22 years, platelet count $330000 \mu \mathrm{L}^{-1} . V$ has been measured by the light microscope (A) and by the light transmission (C) methods which are described in Methods. Double-reciprocal plots of these results are given in (B) and (D), respectively. Error bars in (B) and (D) give the highest and lowest values measured, the point corresponding to the mean of measurements made (usually 2 or 3). For the remaining points in (B) and (D), the deviations in the measurements were less than the width of the point used in preparing the figure. $K^{\prime}$ determined by extrapolating the dotted line to $V^{-1}=0$ was $1.0 \times 10^{-6} M(B)$ and $8.6 \times 10^{-7} M(D) . K^{\prime}$ determined for a number of donors in this way was summarized in the text of Discussion. 
TABLE 1. Comparison of [ADP $]_{1 / 2}$ and $N_{\mathrm{H}}$ for washed platelets and platelets in PRP when $V$ is measured by the light microscope and light transmission methods

\begin{tabular}{l}
\hline \\
\hline Light microscope
\end{tabular}

\section{(a) Fraction of $A D P$ bound}

In testing Eq. 2 by plotting $V^{-1}$ versus $[\mathrm{ADP}]^{-1}$, it is implicitly assumed that the total ADP concentration, [ADP], is approximately equal to $[A D P]_{r}$, i.e., [ADP] $\simeq[\mathrm{ADP}]_{\mathrm{f}}$. An upward curvature for a plot of $V^{-1}$ versus $[A D P]^{-1}$ can occur when a large fraction $(>25 \%)$ of the ADP is platelet bound (Rodbard et al. 1974). A Hill plot at a platelet count of $700000 \mu \mathrm{L}^{-1}$ is compared with that obtained at a count of $40000 \mu \mathrm{L}^{-1}$ in Fig. 4. The fact that $N_{\mathrm{H}}$ is not significantly different at the two platelet counts $(0.1<p<0.25)$ strongly suggests that only a negligible amount of the ADP is platelet bound under the conditions of our experiment.

\section{(b) Plasma factors}

$N_{\mathrm{H}}$ and $[\mathrm{ADP}]_{1 / 2}$ for washed platelets and PRP are compared in Table 1 . As can be seen, $N_{\mathrm{H}}$ remains elevated for washed platelets, but $[\mathrm{ADP}]_{1 / 2}$ is smaller. Al- though these results indicate that the increased sensitivity of washed platelets to ADP may be related to the absence of factors normally present in plasma, it is clear that the elevated value of $N_{\mathrm{H}}$ cannot be explained in these terms.

\section{(c) Platelet shape change reversion}

Under appropriate conditions following ADP-induced platelet shape change, human echinocytes revert spontaneously back to discocytes (Ehrman et al. 1978). The upward curvature shown in Fig. 2 B and D could be explained by assuming that an increased contribution from platelet shape change reversion lowers $V$ at low [ADP]. A plot of $f_{\mathrm{E}}$ versus time following ADP addition when [ADP] is 0.5 and $0.1 \mu M$ is shown in Fig. 5. The former [ADP] corresponds to approximately $K^{\prime}$ and the latter to a concentration which yields $V$ on the upswing portion of a plot of $V^{-1}$ versus [ADP] $]^{-1}$ (see Fig. 2B). 


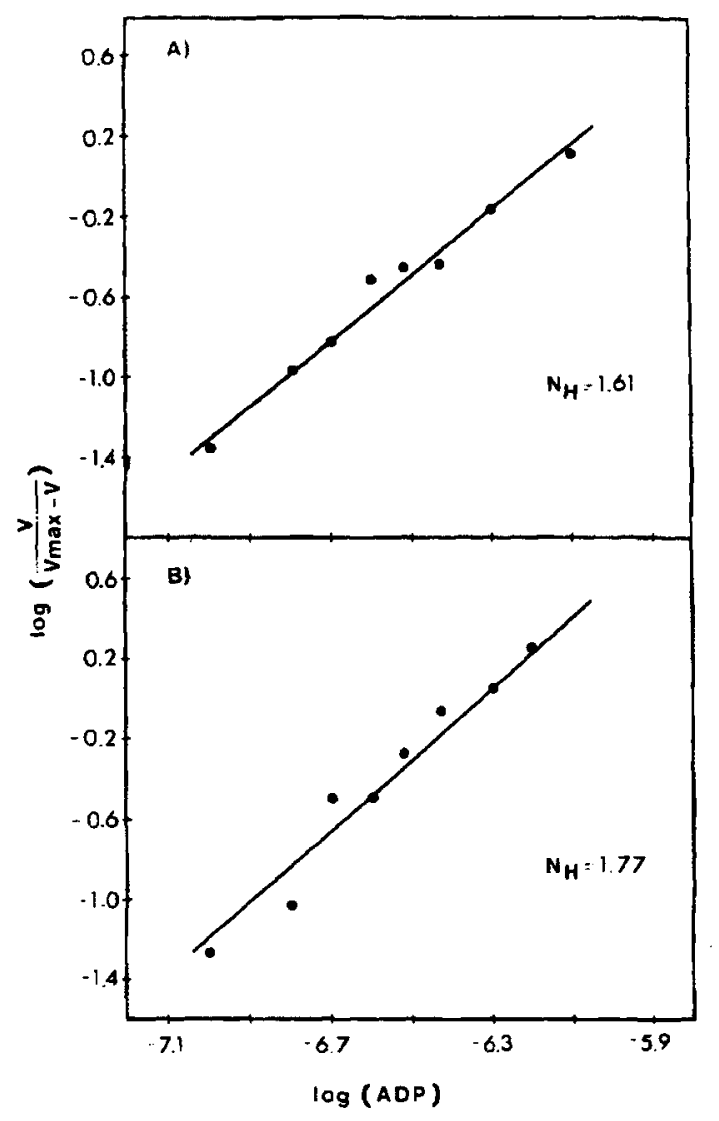

Frc. 3. Comparison of Hill plots for ADP-induced platelet shape change when $V$ is measured by the light microscope method (A) and by the light transmission method (B). Data are taken from Fig. 1. In each case only the linear portion of the Hill plot has been shown. An analysis of covariance as described in Sokal and Rohlf (1969) was used to show that the slopes of these two Hill plots are not significantly different $(0.5>p>0.25)$.

If at a low [ADP] there is an increased contribution of rate of platelet shape change reversion, then we would expect to see that the time which corresponds to maximum $f_{\mathrm{E}}$ is shorter at the lower [ADP]. This expectation is clearly not consistent with the data presented in Fig. 5. Therefore, the upward curvature of a plot of $V^{-1}$ versus $[A D P]^{-1}$ does not arise because of contributions due to platelet shape change reversion. A more detailed analysis of the kinetics of platelet shape change reversion will be presented in a separate communication (Milton, J. G., Glushak, C., and Frojmovic, M. M.: in preparation).

\section{Discussion}

Our results demonstrate that the kinetics of ADPinduced platelet shape change cannot be adequately described by Eq. 2. In particular, our kinetic data yield a value of $N_{\mathrm{H}}>1$ whereas Eq. 2 predicts $N_{\mathrm{H}}=1$. Fur-

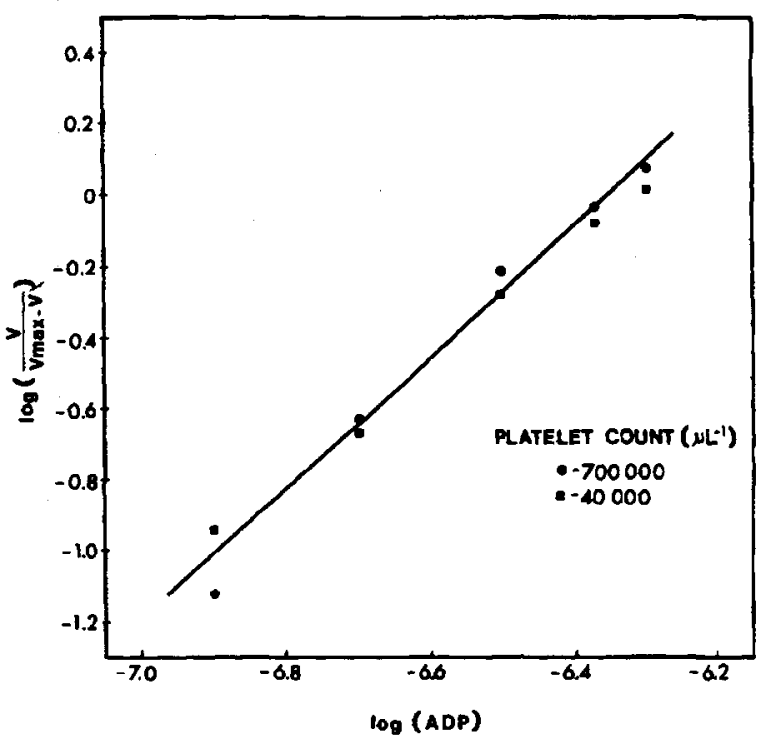

FIG. 4. Comparison of Hill plots for ADP-induced platelet shape change obtained at two different platelet concentrations (donor 2, female). $N_{\mathrm{H}}$ for a platelet count of $700000 \mu \mathrm{L}^{-1}$ was 1.98 and that for a platelet count of $40000 \mu \mathrm{L}^{-1}$ was 1.68 . An analysis of covariance as described in Sokal and Rohlf (1969) was used to show that the slopes of these two Hill plots are not significantly different $(0.25>p>0.10)$. Solid line is that obtained when the data are pooled; $N_{\mathrm{H}}=1.83$.

thermore, we have shown that the property $N_{\mathrm{H}}>1$ is not due to the influence of plasma-borne factors, nor to a large fraction of ADP being platelet bound, nor to an increased rate of platelet shape change reversion at low [ADP]. Karpatkin $(1969 a, 1969 b)$ has demonstrated the existence of subpopulations of platelets which differ with respect to density, size, release reaction, and aggregation. However, binding sites of differing and independent affinities can only lead to $N_{\mathrm{H}}<1 .^{3}$ These observations strongly indicate that the kinetics we are observing reflect processes at the level of the platelet ADP interaction leading to shape change. However, our results do not specify the exact nature of the phenomena at the level of the platelet ADP receptor which result in an elevated $N_{\mathrm{H}}$.

At face value, $N_{\mathrm{H}}>1$ suggests that ADP-induced platelet shape change is a positively cooperative process. This can imply that the binding of an ADP mole-

Indeed when

[3] $\quad V=\sum_{i} \frac{f_{i} V_{\max _{i}}[\mathrm{ADP}]}{[\mathrm{ADP}]+K_{i}^{\prime}}$

where $f_{i}$ is the fraction of receptors (platelets) with distinct $V_{\text {max }_{i}}, K^{\prime}{ }_{i}$, then it can be shown that $\mathrm{d}^{2}\left(\frac{1}{V}\right) / \mathrm{d}\left(\frac{1}{[\mathrm{ADP}]}\right)^{2}<0$ for all positive $f_{i}, K^{\prime}{ }_{i}, V_{\max _{i}}$. Hence a plot of $V^{-1}$ versus [ADP $]^{-1}$ will curve downwards. 


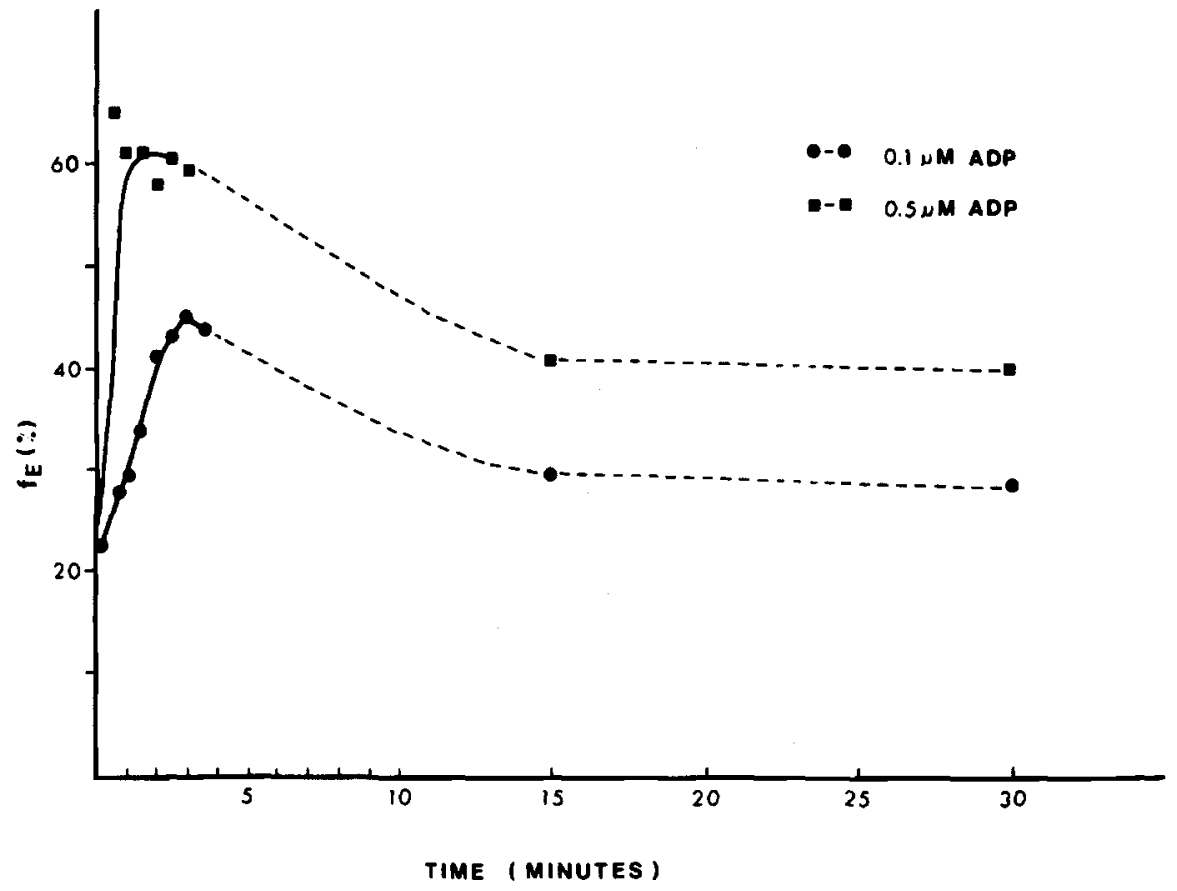

FIG. 5. Fraction of shape-changed platelets $\left(f_{k}\right)$ expressed as a percent, as a function of time following addition of ADP.

cule at one receptor site somehow increases the likelihood of binding of ADP molecules at other receptor sites or that there is a cooperative enzymatic process leading to shape change subsequent to the binding of ADP to the receptor site. Positive cooperativity in membrane receptor mediated processes has been suggested previously (Podleski 1973; Rodbard et al. 1974; Jard et al. 1975).

An elevated value of $N_{\mathrm{H}}$ does not necessarily indicate a positively cooperative process. A value of $N_{\mathrm{H}}>1$ can arise when there is a threshold or "all-or-none" type response either at the level of binding to the receptor (Dixon and Webb 1964) which can arise when the binding of at least two molecules of ADP per receptor site is required to initiate shape change or at the level of the sequence of reactions subsequent to binding which leads to shape change (Rodbard 1973; Goldstein et al. 1974).

Binding studies of ADP to isolated membranes (Nachman and Ferris 1974) and intact platelets (Born and Feinberg 1975) suggest that there is no positive cooperativity at the level of the ADP-receptor binding. This suggests that the apparent positive cooperativity observed in our kinetic measurements arises at a step subsequent to the binding of ADP to the receptor. Previous authors (Podleski 1973; Rodbard et al. 1974) who have observed positive cooperativity in membrane receptor mediated processes have also tended to conclude that the cooperativity is due to processes subsequent to the binding at the receptor. However, Bennett et al (1978) have demonstrated that the number of "true", ADP receptors, $\sim 2500$ per platelet, is much smaller than the number of receptors determined in the earlier studies, e.g., $80000-90000$ per platelet (Born and Feinberg 1975) and $100000-200000$ per platelet (Nachman and Ferris 1974). It is possible that the presence of these additional receptors in the above binding studies masked the cooperativity of the binding of ADP to its "true" receptor. More careful binding studies will be required before the question of the cooperativity of the ADP-receptor binding process, or lack of, can be answered.

Moyle et al. (1976) have pointed out that an elevated $N_{\mathrm{H}}$ may also arise in a situation where there are "spare" receptors, i.e., when maximal response can be elicited when only a small fraction (e.g., 1-2\%) of the available receptor sites are occupied. It is unlikely that the value of $N_{\mathrm{H}}>1$ observed here for ADP-induced platelet shape change can be explained in these terms. Bennett et al. (1978) observed that the maximal velocity of ADPinduced platelet shape change was decreased by the irreversible binding of the inhibitor, $5^{\prime}$-p-fluorosulfonyl benzoyl adenosine, to the ADP receptor sites only after at least 200 such binding sites were occupied by the inhibitor. As these authors estimated that there are $\sim 2500$ "true" ADP receptor sites per intact platelet, this suggests that $V_{\max }$ corresponds to greater than $90 \%$ occupancy of the receptor sites. 
The kinetics of ADP-induced human and rabbit platelet shape change have been examined previously by light transmission methods (Born 1970; Favis and Colman 1978). Although Favis and Colman (1978) do not report a value of $K^{\prime}$ for ADP-induced human platelet shape change, the value of $K^{\prime}$ which can be obtained from the data presented in their communication, $4 \times 10^{-7} \mathrm{M}$, is in excellent agreement with that obtained in our studies from the linear regions of the plots of $V^{-1}$ versus $[\mathrm{ADP}]^{-1}$ (corresponding to $[\mathrm{ADP}] \geqslant 4 \times 10^{-7} \mathrm{M}$ ), namely, $5.2 \times 10^{-7} \pm 2.6 \times 10^{-7}$ (microscope, eight donors) and $4.2 \times 10^{-7} \pm 1.1 \times 10^{-7} M$ (light transmission, six donors). It is of interest to note that closer examination of the data presented by these authors with emphasis placed on the values of $V$ measured at low [ADP] suggested an upward curving $V^{-1}$ versus $[A D P]^{-1}$ plot similar to that reported in this communication.

Although the two methods we have used to measure $V$ are in good agreement (compare, for example, $[\mathrm{ADP}]_{1 / 2}$ in Table 1), it cannot be said that they agree exactly. In particular, $N_{\mathrm{H}}$ determined from light transmission data is typically slightly greater than that determined from data based on platelet morphologies (see Table 1). These differences may in part be due to the relative sensitivity of the two techniques for detecting platelet shape change. With the apparatus at our disposal it was technically more difficult to measure the initial slope of a small decrease in light transmission as opposed to determining directly whether a fraction of platelets have undergone shape change. A limitation of light transmission measurements is that the presence of pseudopods leads to a theoretically predicted increase in light transmission, opposite from the decrease expected for shape change, which is normally associated with pseudopod formation at the earliest stages of activation (Frojmovic 1978). On the other hand, the major limitation of measuring $V$ by direct microscopic observation of platelet morphologies is that it ultimately rests on a subjective decision made on the part of the investigator. Our results do suggest that the differences in kinetics observed between the two methods are small enough that they can be used interchangeably for most practical purposes, as, for example, determining $[\mathrm{ADP}]_{1 / 2}$.

A number of phenomena have been observed and (or) suggested to occur in conjunction with ADP-induced platelet shape change including the dissolution of the circumferential band of microtubules (White 1968), mobilization of intracellular $\mathrm{Ca}^{2+}$ (Grette 1962; Kinlough-Rathbone et al. 1975), and phosphorylation of ADP to ATP (Guccione et al. 1971; Mustard et al. 1975). Whichever of these processes is important for platelet shape change, it is clear that any proposed mech- anism for shape change should also provide an explanation for the observed kinetics of the process. It is anticipated that careful studies with the actual ADP receptor molecule, possibly the 100000 molecular weight membrane polypeptide isolated by Bennett et al. (1978), in light of the results reported here will greatly facilitate the search of the mechanism for platelet shape change.

\section{Acknowledgment}

The authors wish to acknowledge the technical assistance of $E$. Toth and $Y$. Ayroud during the early development of the microscopic methods used in this study.

Bennett, J. S., R. F. Colman, and R. W. Colman. 1978. Identification of adenine nucleotide binding proteins in human platelet membranes by affinity labelling with $5^{\prime}-p-$ fluorosulfonyl benzoyl adenosine. J. Biol. Chem. 253, $7346-7354$.

BoRN, G. V. R. 1965. Uptake of adenosine and of adenosine diphosphate by human blood platelets. Nature (London), 206, 1121-1122.

1970. Observations on the change in shape of blood platelets brought about by adenosine diphosphate. J. Physiol. (London), 209, 487-511.

Born, G. V. R., and H. FeInberg. 1975. Binding of adenosine diphosphate to intact human platelets. J. Physiol. (London), 251, 803-816.

CI.ARK, A. J. 1926. The antagonism of acetylcholine by atropine. J. Physiol. (London), 61, 547-556.

DixON, M., and E. C. Weks. 1964. Enzymes. 2nd ed. Longmans, London. pp. 81-84.

Ehrman, M., E. Toth, and M. Frojmovic. 1978. A platelet procoagulant activity associated with platelet shape change. J. Lab. Clin. Med. 92, 393-401.

FAvis, G. R., and R. W. Colman. 1978. The action of halofenate on platelet shape change and prostaglandin synthesis. J. Lab. Clin. Med. 92, 45-52.

Frojmovic, M. M. 1973. Quantitative parameterization of the light transmission properties of citrated, platelet-rich plasma as a function of platelet and adenosine diphosphate concentrations and temperature. J. Lab. Clin. Med. 82, 137-153.

1978. Rheooptical studies of platelet structure and function. In Progress in hemostasis and thrombosis. Vol. 4. Edited by T. H. Spaet, Grune \& Stratton Inc., New York. pp. 279-319.

Frojmovic, M. M., and R. Panjwani. 1976. The geometry of normal mamnalian platelets by quantitative microscopic studies. Biophys. J. 16, 1071-1089.

Gol.pstein, A., L. Aronow, and S. M. Kal.man. 1974. Principles of drug action: The basics of pharmacology. John Wiley and Sons (Canada) Ltd., Toronto. pp. 96-98.

GretTE, K. 1962. Studies on the mechanism of thrombincatalyzed hemostatic reactions in blood platelets. Acta Physiol. Scand. 56 (Suppl. 195), 1-93.

Guccione, M. A., M. A. Packham, R. L. KinioughRATHBONE, and J. F. Mustard. 1971. Reactions of ${ }^{14} \mathrm{C}$ ADP and ${ }^{14} \mathrm{C}$-ATP with washed platelets from rabbits. Blood, 37, 542-555.

JARD, S., C. ROY, T. Barth, R. Rajerison, and J. BoCHAERT. 1975. Antidiuretic hormone-sensitive kidney adenylate cyclase. Adv. Cyclic Nucleotide Res. 5, 31-52. 
KARPATKIN, S. 1969a. Heterogeneity of human platelets.I. Metabolic and kinetic evidence suggestive of young and old platelets. J. Clin. Invest. 48, 1073-1082.

$1969 \mathrm{~b}$. Heterogeneity of human platelets. II. Functional evidence suggestive of young and old platelets. J. Clin. Invest. 48, 1083-1087.

Kiniough-Rathbone, R. L., A. Cahil,, M. A. Packham, H.-J. Reimers, and J. F. Mustard. 1975. Effect of ionophore A23,187 on thrombin-degranulated washed rabbit platelets. Thromb. Res. 7, 435-449.

Mil.ls, D. C. B., and D. E. Macrari.ANE. 1975. Platelet receptors. In Platelets in biology and disease. Edited by J. L. Gordon. North-Holland, New York, pp. 159-202.

Milton, J. G., and M. M. Frojmovic. 1979. Shape changing agents produce abnormally large platelets in a hereditary "giant platelet syndrome (MPS)." J. Lab. Clin. Med. 93, 154-161.

Moyle, W. R., E. Y. Lee, O. P. Bahl, J. E. Garfink, and D. RoIBARD. 1976. New method of quantifying ligand binding based on measurement of an induced response. Am. J. Physiol. 232, E274-E285.

Mustard, J. F., M. A. Packham, D. W. Perry, M. A. GucCIONE, and R. I. KINIOUGH-RATHBone. 1975. Enzyme activities on the platelet surfaces in relation to the action of adenosine diphosphate. Ciba Found. Symp. 35, 47-70.

Mustard, J. F., D. W. Perry, N. G. Ardif, and M. A.
PaCkham. 1972. Preparation of suspensions of washed platelets from humans. Br. J. Haematol. 22, 193-204.

NACHMAN, R. L., and B. Ferris. 1974. Binding of adenosine diphosphate by isolated membranes from human platelets. J. Biol. Chem. 249, 704-710.

PoDleski, T. R. 1973. Cooperativity of the electroplax membrane. In Drug receptors. Edited by H. P. Rang. University Park Press, Baltimore, pp. 135-148.

RODBARD, D. 1973. Theory of hormone-receptor interaction. II. The endocrine cell as a quantal response unit. A general control mechanism. Adv. Exp. Med. Biol. 36, 342-364.

Rovbard, D., W. R. MoYle, and J. Ramachandran. 1974 Apparent positive cooperativity in the mechanisms of luteinizing hormone. In Hormone binding and target cell activation of the testis. Edited by M. L. Dufau and A. R. Means. Plenum Publishing Corporation, New York. pp. 79-87.

Sokal, R. R., and F. J. Rohlf. 1969. Biometry. W.H. Freeman \& Company, San Francisco.

TANG, S. S., and M. M. Frojmovic. 1977. The effects of $p \mathrm{CO}_{2}$ and $\mathrm{pH}$ on drug-induced platelet sphering and aggregation for human and rabbit platelet rich plasma. Thromb. Res. 10, 135-145.

White, J. G. 1968. Fine structural alterations induced in platelets by adenosine diphosphate. Blood, 31, 604-622. 